\title{
Los medios de comunicación y los límites de la rendición de cuentas en democracias no consolidadas
}

\author{
El caso de México
}

\author{
The Media and the Limits of Accountability \\ in Unconsolidated Democracies:The Case of Mexico
}

Manuel Alejandro Guerrero y Andrés Castillo*

\begin{abstract}
Resumen: Una característica importante en regímenes que en algún punto iniciaron procesos de liberalización política, tiene que ver con el incremento en la diversidad y la libertad de expresión en los medios. Sin embargo, en aquellos regímenes que luego de iniciar tales procesos no han logrado transitar exitosamente hacia formas de democracia consolidadas, la diversidad y la libertad de expresión mediáticas no se traducen en funciones más efectivas de vigilancia contra los abusos de poder (watchdog role), no solo debido a que el compromiso de los gobiernos con la rendición de cuentas es más discursiva que real, sino también porque la divergencia informativa en la cobertura de estos temas les resta fuerza ante la opinión pública. En este trabajo se compara la cobertura de dos escándalos de supuesta corrupción: la "Casa Blanca" del presidente Peña Nieto y "las Casas" del director de la Comisión Federal de Electricidad (CFE), Manuel Bartlett. A pesar de tratarse de dos gobiernos distintos, la impunidad resultante, si bien obedece a la falta de compromiso institucional de la agencia responsable, también responde a la incapacidad mediática de construir una narrativa alternativa y distinta frente al tema de la corrupción.
\end{abstract}

Palabras clave: corrupción, democracia, medios de comunicación, México, periodismo, responsabilidad.

Abstract: An important characteristic in regimes that at some point began political liberalization processes has to do with the increase in diversity and freedom of expression in the media. However, in those regimes that after initiating such processes have not been able to

* Manuel Alejandro Guerrero es director del Departamento de Comunicación de la Universidad Iberoamericana, Prol. Paseo de la Reforma 880, Lomas de Santa Fe, 01219, Ciudad de México. Tel: 555950 4000, ext: 4037//55 5950 4037. Correo-e: alejandro.guerrero@ibero.mx. orciD: https://orcid.org/00000002-1921-5402. Andrés Castillo es asistente de investigación en el Departamento de Comunicación de la Universidad Iberoamericana, Prol. Paseo de la Reforma 880, Lomas de Santa Fe, 01219, Ciudad de México. Tel: 557109 5629. Correo-e: andres.castillo@ibero.mx. orCiD: https://orcid.org/0000-0001-6329-4745.

Artículo recibido el 30 de septiembre de 2020 y aceptado para su publicación el 26 de marzo de 2021. 
successfully transit towards consolidated forms of democracy, diversity and freedom of expression in the media do not translate into more effective surveillance functions against abuses of power (watchdog role), not only because the governments' commitment to accountability is more discursive than real, but also because the informational divergence in the coverage of these issues reduces their strength in public opinion. This paper compares the coverage of two alleged corruption scandals: the "White House" of president Peña Nieto and "The houses" of the director of the Federal Commission of Electricity, Manuel Bartlett. Despite being two different governments, the resulting impunity, although due to the lack of institutional commitment of the responsible agency, also responds to the inability of the media to construct an alternative and different narrative on the issue of corruption.

Keywords: corruption, democracy, media, Mexico, journalism, responsibility.

\section{INTRODUCCIÓN}

T Tna característica importante en regímenes que en algún punto iniciaron procesos de liberalización política tiene que ver con el incremento en la diversidad y la libertad de expresión en los medios. Sin embargo, en aquellos regímenes que luego de iniciar tales procesos no han logrado transitar exitosamente hacia formas de democracia consolidadas, la diversidad y la libertad de expresión mediáticas no se traducen en funciones más efectivas de vigilancia (watchdog role) contra los abusos de poder, no sólo debido a que el compromiso de los gobiernos con la rendición de cuentas es más discursiva que real, sino también porque se carece de un interés común en la cobertura de estos temas entre los propios medios, que en general privilegian el ángulo del escándalo sobre el del análisis y la información, incumpliendo así una de las funciones clave que tienen en las democracias. Esta condición se agudiza en contextos en donde, además, el Estado no garantiza las condiciones básicas para un ejercicio profesional del periodismo investigativo en donde los periodistas puedan exponer los temas sin temor a la censura o incluso poner en riesgo su integridad física.

En México, si bien desde finales del siglo xx se ha logrado establecer procesos electorales relativamente abiertos y competitivos, todavía persisten serios desafíos en relación con el estado de derecho, la transparencia, la responsabilidad pública y la rendición de cuentas. En el campo de la información, el régimen posrevolucionario había gestado un sistema complejo de intercambios de beneficios por apoyos políticos con los medios de comunicación con base en diferentes mecanismos —desde las compensaciones salariales otorgadas por dependencias gubernamentales y el peso de la publicidad oficial no regulada y discrecional, hasta las relaciones de cercanía de editores y dueños de medios con grupos políticos (Guerrero, 2011)_. Una relación de intercambio que, en caso de no hacerse 
efectiva por parte de los medios, resultaba en la aplicación de duros mecanismos de censura. El resultado se reflejaba en una labor informativa con escasos incentivos para la investigación.

Todo esto significaba una seria distorsión del papel de vigilancia que debía cumplir la información. En este sentido, una fuerte expectativa que despertaron las alternancias en el poder a nivel federal desde 2000 era la de transformar eventualmente las formas del quehacer periodístico que había marcado el régimen anterior. No obstante, si bien hoy se tiene un panorama mediático más plural y diverso, no necesariamente se tienen mejores prácticas informativas de vigilancia y de profesionalismo periodístico.

Este trabajo compara la cobertura de dos escándalos de supuesta corrupción: la Casa Blanca del presidente Peña Nieto y las Casas del director de la Comisión Federal de Electricidad (CFE), Manuel Bartlett. A pesar de tratarse de dos gobiernos distintos, la impunidad resultante, si bien obedece a la falta de compromiso institucional de la agencia responsable (la misma Secretaría de la Función Pública), por lo que corresponde a la cobertura informativa, salvo excepciones, esta se centra en su conjunto en aspectos que privilegian los dichos de actores políticos — favorables y críticos_ más que el análisis de los hechos, por lo que se termina por favorecer el escándalo mediático. Escándalos a partir de los cuales es difícil suponer que favorezcan una opinión pública mejor informada, pero probablemente sí más desencantada del sistema político en su conjunto. Por lo tanto, cabe preguntarse sobre el papel de los medios en la forma en que se publicitan y se informan los temas relacionados con la corrupción y la rendición de cuentas.

\section{MEDIOS EN DEMOCRACIAS NO CONSOLIDADAS: EL CASO DE MÉXICO}

La democracia, como cualquier otro tipo de régimen, supone formas específicas de acceder al poder y de ejercerlo. En buena medida, los atributos con los que Robert Dahl (1971) definía a las poliarquías comprenden las formas de acceso al poder: libres, competitivas, equitativas y participativas. Se puede sintetizar entonces que en un régimen democrático las formas de acceso deben ser abiertas. Por su parte, las formas de ejercicio del poder en una democracia se definen por ser limitadas y equilibradas. Limitadas en el sentido de las formas en que el poder del régimen se extiende en la sociedad (Dunn, 1999). Aquí se habla, por ejemplo, de criterios relativos a la existencia efectiva de un estado liberal de derecho que limita el poder público frente a los derechos y libertades de individuos y grupos, pero también de criterios de responsividad y de cierto tipo de rendición de cuentas 
y de transparencia. El equilibrio, en cambio, tiene que ver con las formas en que el poder se distribuye y se comparte entre diferentes órdenes e instituciones (O’Donnell, 1998). Se trata de criterios relativos a pesos y contrapesos y, nuevamente, a ciertas formas de rendición de cuentas y de transparencia. Se puede sintetizar entonces que, en un régimen democrático, las formas de ejercer el poder deben ser responsables.

Así, en una democracia se esperaría que los medios de comunicación, cuya agenda constituye un espacio donde los distintos actores expresan sus opiniones y posicionamientos en relación con un conjunto de decisiones gubernamentales de interés público (Del Castillo Alemán y Flores Ivich, 2019), operaran en condiciones de aceptable diversidad e independencia frente al poder con el fin de cumplir relativamente bien con sus funciones esenciales de informar, vigilar (watchdog) y servir como arena de debates en asuntos de interés público. Muchos países que iniciaron procesos de transición han sido capaces de construir reglas más o menos abiertas de acceso al poder, pero no necesariamente reglas para un ejercicio del poder más responsable. En estos regímenes de democracias no consolidadas, esto significa que, si bien es posible encontrarse con un panorama mediático relativamente diverso y plural, la independencia mediática queda condicionada por la aplicación de reglas que terminan por distorsionar alguna o varias de sus funciones informativas, sobre todo la de vigilancia contra los abusos de poder.

En el caso de México, el país iniciaba el siglo xxi como parte de los países que habían logrado resolver, aparentemente, los conflictos derivados de la competencia por el poder mediante mecanismos electorales abiertos a la participación y cuyos resultados, en general, terminaban acatándose en los hechos por todas las partes en contienda. Esto no significa que, a pesar de las reformas y los mecanismos legales, no siguiese habiendo problemas de fiscalización de campañas y partidos, ni que se hubieran logrado erradicar las prácticas clientelares y el desvío de recursos. Lo que significa es que se crearon vías institucionales a las cuales recurrir en tales casos. Así, es posible afirmar que, con todo, en México se han ido consolidando las formas abiertas de acceso al poder fundamentadas en la actuación de organismos relativamente autónomos, como el Instituto Nacional Electoral y el Tribunal Electoral, pero sobre todo en la participación ciudadana y en el voto.

Algunos de los aspectos más socorridos de las teorías de la democracia indican que este tipo de regímenes generan incentivos para reducir la corrupción y favorecen una mayor vigilancia mediante mecanismos de rendición de cuentas verticales, horizontales y “societales" (Dahl, 1971; O’Donnell, 1998). En principio, la oposición tendría todos los incentivos para vigilar y exponer los abusos de poder, 
las malas prácticas y la corrupción de los gobiernos en turno con miras a lograr triunfos electorales y, al mismo tiempo, los electores tendrían todo el interés de castigar a los malos gobiernos (Myerson, 1993; Ades y Di Tella, 1999; Kunicová, 2006). Sin embargo, en México los actores políticos llegados mediante el voto popular durante las alternancias (2000-2018) han carecido de los incentivos adecuados para avanzar hacia formas plenas de responsabilidad política y rendición de cuentas. Estos actores, si bien han propiciado la creación de instituciones y han impulsado reformas muy importantes tendientes hacia un ejercicio más responsable del poder - desde las leyes de transparencia hasta el Sistema Nacional Anticorrupción - , en realidad han carecido de la voluntad política suficiente para volverlas realmente eficaces o, simplemente, ponerlas en marcha. Las élites políticas han preferido acomodarse a la práctica de las viejas reglas de un ejercicio de poder poco responsable y sustituir la vigilancia mutua por acuerdos y arreglos políticos en detrimento de la rendición de cuentas.

Por su parte, al menos hasta el gobierno del presidente Peńa Nieto (2012-2018), esta falta de voluntad de los actores políticos para impulsar cambios de fondo en las formas del ejercicio del poder fue aprovechada por la mayoría de los medios de comunicación convencionales para negociar también viejas formas de intercambio de beneficios por apoyo con la clase política y mantener negocios redituables en lugar de haber impulsado nuevas formas más profesionales y vigilantes de periodismo. En este sentido, las viejas prácticas de intercambio vigentes durante el régimen priista, no se terminaron, sino que se diversificaron. Ahora, la competencia política abría más oportunidades de negocio para los medios en 32 entidades federativas, más varios municipios con los recursos suficientes como para pagarse una "buena prensa". Los medios - y algunos periodistas en sus espaciosno sólo se beneficiaron de la publicidad gubernamental, sino de la venta de entrevistas a modo y de la inserción de gacetillas e infomerciales propagandísticos que se insertaban como información. Así, en términos generales, el quehacer periodístico, al menos el de una buena parte de los medios convencionales, lejos de profesionalizarse con las alternancias, mantuvo los mismos vicios y limitaciones del periodo anterior. El resultado se reflejaba en una labor informativa con escasos incentivos para la investigación, y que seguía siendo altamente dependiente de los boletines y de las declaraciones de los actores públicos.

Paralelamente a la continuación de las relaciones de tipo clientelar entre los medios y el poder, en México se acentuó en el nuevo siglo la delicada situación de la inseguridad, aspecto que ha sido particularmente nocivo para el proceso de desarrollo profesional de la prensa en el país. 
El fracaso del Estado en lo que concierne a garantizar las condiciones de seguridad elementales para ejercer el periodismo de investigación en México se refleja en la cifra de agresiones contra la prensa que se ha registrado en las últimas dos décadas. Durante el sexenio del presidente Felipe Calderón se registraron 48 periodistas asesinados en el país, mientras que en el de Enrique Peña Nieto hubo 47. Con el propósito de atender este asunto, en 2011 se creó la Fiscalía Especial para la Atención de Delitos cometidos contra la Libertad de Expresión (FEADLE). Dicha fiscalía, a más de ocho años de su creación, solo ha conseguido cuatro sentencias condenatorias de 803 averiguaciones previas.

Es claro que los escándalos de corrupción, la inseguridad, el abuso y la incapacidad para resolver las diferentes desigualdades de los gobiernos del periodo 2000-2018 contribuyeron, sin duda, a generar un clima favorable de cambio que sería aprovechado por Andrés Manuel López Obrador, en su tercera candidatura a la presidencia, en el proceso electoral de 2018. Con su victoria, se esperaban cambios importantes de fondo en el ejercicio del poder y en la relación del Estado con la sociedad. En el campo de la información, una fuerte expectativa era la de transformar también el quehacer periodístico que había marcado el régimen anterior basado en un sistema complejo de intercambios de beneficios por apoyo político entre el régimen y los medios, al igual que avanzar en lo que respecta a la garantía de condiciones de seguridad para ejercer el periodismo y la reducción de mecanismos de censura.

En este sentido, a lo largo de la campaña, el candidato López Obrador enfatizó temas relativos al fin de la violencia y de la corrupción, un auténtico combate a la impunidad, una reforma de fondo en el modo de operar el gobierno y un desarrollo incluyente que mirara, fundamentalmente, en favor de los grupos más vulnerables en lugar de enfatizar la competitividad, la apertura y el crecimiento. Con todo, a dos años de iniciado su gobierno los datos no muestran los resultados esperados en la reducción de las violencias, ni tampoco en el combate a la impunidad y, por si fuera poco, la pandemia mundial de covid-19 ha empeorado el panorama económico, generando pronósticos de decrecimiento nunca vistos cercanos a -9 por ciento del producto interno bruto (PIB) de acuerdo con estimaciones del Banco de México (Flores, 2020). En cuanto a las medidas tendientes a fortalecer un ejercicio de poder responsable, las decisiones tomadas hasta el momento en relación con el funcionamiento del aparato estatal, indican más bien su desmantelamiento a partir no solo del profundo desdén por la planeación, implementación y evaluación de política pública, sino del debilitamiento completo del sector público con base en recortes indiscriminados. 
En cuanto al panorama informativo, el gobierno del presidente López Obrador se ha definido por tres aspectos: 1) un intento por cambiar el modelo de relación con los medios a partir del uso de la publicidad oficial; 2) una centralización de la comunicación gubernamental con base en conferencias diarias y redes sociodigitales, y 3) confrontación directa con la prensa.

\section{Modelo de relación con los medios}

Entre enero y abril de 2019 se aprobaron diversas disposiciones en relación con las campańas de publicidad oficial y con las políticas de comunicación del gobierno federal (DOF, 2019a; 2019b). En ellas se establece una reducción de 50 por ciento en el gasto de comunicación social, límites, prohibiciones y sanciones contra el uso propagandístico personal de este rubro y pagos por entrevistas e inserciones con fines periodísticos. Estas medidas representan una ruptura histórica con el viejo modelo de relación entre medios y régimen, aunque se debe señalar que no están consagradas en ley, ni tampoco se han establecido criterios claros de asignación que eviten la discrecionalidad (Artículo 19, 2020a). Más aún, la discrecionalidad del gobierno quedó manifiesta en la súbita decisión del presidente López Obrador de devolver a los radiodifusores un porcentaje de los tiempos fiscales sin mayor explicación que la que el propio presidente ofreció en su conferencia del 22 de abril de 2020 cuando dijo que "el gobierno no necesita publicidad oficial, pues mantiene una comunicación constante con el pueblo".

\section{Centralización de la comunicación}

Ha sido precisamente la centralización de la comunicación gubernamental a través de las conferencias diarias, llamadas coloquialmente "mañaneras", la manera en que el presidente López Obrador ha decidido utilizar para dos propósitos: definir de forma centralizada la agenda pública y circundar la intermediación de

\footnotetext{
${ }^{1}$ Los "tiempos fiscales" para la radiodifusión fueron una medida implementada por el gobierno de Gustavo Díaz Ordaz en 1969 para que los medios de comunicación pagaran impuestos equivalentes a un gravamen de 25 por ciento de los ingresos facturados de las empresas concesionarias. La alternativa al pago de este impuesto era hacerlo "en especie" mediante la cesión al gobierno de 12.5 por ciento de tiempo diario de transmisión que, en principio, se utilizaría para campañas públicas. En realidad, el gobierno nunca tuvo la capacidad de producir tal cantidad de contenidos como para ocupar ese tiempo, que no era acumulable y que al final de cuentas funcionaba como espacio de negociación e intercambio también. En el gobierno del presidente Vicente Fox (2000-2006) este acuerdo se modificó y los "tiempos fiscales" en favor del gobierno se redujeron a solo 18 minutos diarios de transmisión en televisión y 35 minutos en radio. Ahora, con este nuevo decreto del presidente López Obrador, los "tiempos fiscales" quedan en 11 minutos para la TV y 21 minutos para la radio $(D O F, 2020)$.
} 
los medios en el proceso informativo. Para ello, el mensaje del presidente cobra eco a través de las redes sociodigitales que, cada vez más polarizadas, han constituido, en general, dos bandos muy claros: aquellos que defienden al presidente y su proyecto y quienes lo critican. Con todo, ha sido el propio presidente quien ha fomentado, en buena medida, esta polarización en los ámbitos de discusión de la vida pública. Prácticamente desde el inicio de su mandato, ha aprovechado sus conferencias diarias para construir en su discurso a enemigos reales e imaginarios a quienes ha definido explícitamente como conservadores opuestos al cambio e, implícitamente, como enemigos del pueblo.

\section{Confrontación con la prensa}

Dentro del grupo de conservadores, el presidente López Obrador se ha referido a muchos de los principales medios convencionales - desde Reforma, El Universal, Milenio y hasta Proceso-, así como a periodistas específicos. En abril de 2019, en relación con una participación anterior del periodista Jorge Ramos en la conferencia "mañanera" en donde hizo comentarios críticos sobre las cifras de homicidios y la libertad de prensa, el presidente expresó que los periodistas debían ser prudentes en sus comentarios, "porque si ustedes se pasan, pues ya saben, ¿no?, lo que sucede [en relación con la andanada de ataques que recibió Ramos por parte de los seguidores del presidente en las redes sociodigitales]... no soy yo, es la gente" (Animal Político, 2019). Este tipo de señalamientos es una nueva variante en el abanico de agresiones contra la prensa. El presidente López Obrador ha argumentado que es el presidente más atacado de la historia del país, incluso presentando estudios de opinión que su propio equipo de comunicación y propaganda realiza, como lo hizo en su conferencia mañanera del 15 de octubre de 2020, mostrando nombres de aquellos periodistas que más lo critican. Ha argumentado también que los periodistas tienen derecho a criticar y que él tiene derecho a defenderse. Lo cierto es que hoy en día cuestionar e investigar sobre el actuar del gobierno deriva, en muchas ocasiones, en ataques organizados en redes sociales que no tienen el carácter de debate crítico sino, por el contrario, buscan organizar y manipular el entorno social o mediático con el fin de aislar, derribar o intimidar a los opositores ideológicos.

Tras otros muchos ejemplos de crítica y advertencia a la labor informativa, el 23 de abril el presidente señalaba abiertamente en otra conferencia que, "en México, no hay un periodismo profesional", tras lo cual señaló a varios periodistas por su nombre (Jiménez y Urrutia, 2020). En un país con cerca de 140 asesinatos de periodistas entre 2000 y 2019 , este tipo de aseveraciones incrementan 
el riesgo bajo el cual reporteras y reporteros llevan a cabo sus funciones. De acuerdo con cifras de Artículo 19, durante la administración actual se tienen registrados 13 casos a mayo de 2020 (Artículo 19, 2020b).

Frente a esta situación, las oportunidades para profesionalizar el quehacer periodístico siguen desaprovechadas, pues también falta voluntad. Ante la aún muy significativa dependencia económica que tienen los medios de los ingresos provenientes del gobierno y la agresividad de la respuesta del ejecutivo ante la crítica, los medios han dedicado buena parte de sus espacios a señalar los errores que comete el presidente en sus conferencias y las incongruencias de su discurso frente a decisiones con un afán mayor de exhibir personalmente al titular del Ejecutivo, a algunos de sus más cercanos colaboradores y destacar escándalos mediáticos, que a analizar con detenimiento la vida pública y a ofrecer mayor contexto a sus audiencias.

\section{LOS CASOS DE ESTUDIO: CASA BLANCA Y LAS CASAS DE BARTLETT}

Para analizar la cobertura de estos dos casos que inicialmente aparecieron como reportajes en dos espacios informativos, MVS Primera Emisión (Carmen Aristegui) y Asi las Cosas con Loret en W Radio (Carlos Loret de Mola), se eligieron diez diferentes espacios informativos que incluyen prensa escrita, radiodifusión (radio y TV) y portales digitales. En el caso de la TV, la selección incluye los dos espacios informativos nacionales en XEW-TV de Televisa y XHDF de TV Azteca. En el primer caso, el programa era Noticiero con Joaquín López Dóriga durante el periodo de cobertura de la Casa Blanca y En Punto con Denise Maerker durante la cobertura de Bartlett Bienes Raíces. En el caso de TV Azteca, el noticiero fue en los dos casos Hechos de la Noche con Javier Alatorre. En el caso de los noticieros radiofónicos, la selección fue aleatoria con base en los datos de los primeros 15 espacios escuchados con base en el ranking de INRA para 2014 (Arreola, 2015) y de Ipsos publicado en abril de 2020 (Ipsos, 2020). Los espacios seleccionados fueron el de Ciro Gómez Leyva Por la Mañana en Radio Fórmula y el de Carmen Aristegui, quien durante la cobertura del tema de la Casa Blanca estaba al frente de MVS Primera Emisión y durante el de Bartlett Bienes Raíces en Aristegui en Vivo (tanto a través de su propia plataforma digital como en convenio con Grupo Radio Centro). Asimismo, la selección de periódicos se hizo de forma aleatoria con base en una lista de este tipo de medios con tiraje y cobertura nacional desde la Ciudad de México. De ahí se seleccionaron La Jornada, Reforma, Milenio y La Razón. Finalmente, se tomaron los dos portales informativos digitales más relevantes en función de su reconocimiento, prestigio 
e impacto en la discusión de asuntos de interés general y de ahí se seleccionaron Animal Politico y Sin Embargo.

Para la información relativa al caso de la Casa Blanca se utilizó una base de datos de la empresa Eficiencia Informativa (Efinfo) y para el caso Bartlett Bienes Raíces una serie de recursos digitales propios de la Universidad Iberoamericana. Las unidades de análisis fueron todas las notas, reportajes y entrevistas, y se dejaron fuera las columnas de opinión y los editoriales. En ambos casos, el análisis de la cobertura incluye el día en que estos temas aparecen por vez primera en los medios hasta los dos días posteriores a la fecha en que los correspondientes titulares de la Secretaría de la Función Pública (SFP) anuncian el "cierre" de las investigaciones y establecen una conclusión de cada caso. Para cada unidad de análisis se estudió el título, el tono, la adjetivación en el texto y el número y variedad de las fuentes citadas, que pueden ser favorables en relación con la "narrativa gubernamental" o críticas al respecto, es decir coincidir con la "narrativa de los reportajes" (véanse los casos abajo). En relación con la variedad de las fuentes, estas se han dividido en "oficiales y pro gubernamentales", que incluye a todos aquellos que son favorables a la narrativa oficial (funcionarios, expertos y periodistas) y "críticas", que incluye políticos de oposición, expertos, académicos y periodistas que coinciden con la narrativa de los reportajes iniciales. Se consideran solo aquellas intervenciones que explícitamente apoyan una u otra narrativa. La narrativa gubernamental se refiere a las posiciones presentadas por parte de los voceros autorizados del gobierno — el presidente Peńa Nieto, su vocero, su esposa y el secretario de la Función Pública, en el primer caso, y el presidente López Obrador, el director de la Comisión Federal de Electricidad y la secretaria de la Función Pública, en el segundo-. Como unidades favorables se registran todas las piezas que reproducen o apoyan la posición gubernamental, mientras que como críticas se registran aquellas que apoyan la narrativa de los reportajes iniciales. No hay unidades neutrales debido a que se considera que las piezas que "solo" reproducen una u otra narrativa implícitamente marcan un encuadre favorable a ella. A continuación, se presenta cada caso.

\section{La Casa Blanca}

El 8 de noviembre de 2014, MVS Primera Emisión con Carmen Aristegui presentó un reportaje titulado "La Casa Blanca de Enrique Peña Nieto", realizado por su unidad de investigación apoyado en la plataforma de periodismo latinoamericano Connectas y el International Center for Journalists (Aristegui Noticias, 2014). Este reportaje su publicó de forma conjunta en el semanario Proceso y en el periódico 
La Jornada. En él se indica que el presidente Peña y su familia habían hecho uso, como domicilio particular, de una residencia con un valor aproximado de $7 \mathrm{mi}$ llones de dólares, la cual era hasta entonces propiedad de Ingeniería Inmobiliaria del Centro, una empresa del Grupo Higa. El reportaje documenta que este grupo constructor, a través de sus diferentes filiales, había obtenido varias licitaciones para la construcción de obra pública durante la gubernatura de Enrique Peña Nieto en el Estado de México: desde la edificación y operación del Hospital Regional de Especialidades de Zumpango (obra por la que el gobierno pagaría 7030 mil millones de pesos a lo largo de 23 años), hasta diversas obras viales — como las autopistas Toluca-Naucalpan y Toluca Atlacomulco, y el distribuidor Naucalpan-Metepec- De acuerdo con este reportaje, que cita documentos obtenidos vía solicitudes de transparencia, en ese periodo Grupo Higa y sus filiales obtuvieron contratos por más de 8 mil millones de pesos (Aristegui Noticias, 2014: 6). Finalmente, otras filiales del grupo emitieron facturas al Partido Revolucionario Institucional (PRI) y al equipo de campańa de Enrique Peña Nieto durante las elecciones presidenciales de 2012 (Aristegui Noticias, 2014: 6).

Un día después de que se publicó el reportaje, el vocero de la Presidencia, Eduardo Sánchez, afirmó en diversos espacios informativos que la llamada Casa Blanca era un inmueble que la esposa del presidente Peńa, la señora Angélica Rivera, estaba adquiriendo a plazos con base en sus propios recursos. Indicó, además, que el inmueble había sido adquirido en enero de 2012 —antes de iniciar las campañas presidenciales- y que, en efecto, aún se encontraba a nombre de la inmobiliaria señalada en el reportaje. A estas declaraciones siguió una nota informativa oficial de la Presidencia (La Silla Rota, 2014) en la que se aclara textualmente que:

1. En enero de 2012, la señora Angélica Rivera Hurtado celebró un contrato con Ingeniería Inmobiliaria del Centro, S.A. de C.V., por virtud del cual la primera se compromete a adquirir los inmuebles marcados con los números 150 y 160 de la calle Sierra Gorda, los cuales eran propiedad de esta inmobiliaria desde 2009 y 2010. Es importante destacar que dichos inmuebles colindan con la casa que, desde varios años atrás, ya era propiedad de la señora Angélica Rivera Hurtado y que el objeto de adquirirlos era ampliar el espacio de su casa habitación.

2. La señora Angélica Rivera Hurtado, quien contrajo matrimonio con el Lic. Enrique Peńa Nieto el 27 de noviembre de 2010, bajo el régimen de separación de bienes, es económicamente solvente y contaba con recursos suficien- 
tes para adquirir estos inmuebles. La larga carrera profesional de la señora Rivera Hurtado le ha permitido consolidar su patrimonio personal.

3. La señora Angélica Rivera Hurtado pagó a la firma del contrato, en enero de 2012, casi un año antes de que su esposo fuera presidente de la República, el 30 por ciento del total del precio pactado, lo que hizo mediante la emisión de un cheque nominativo, de su cuenta personal, a favor de la empresa Ingeniería Inmobiliaria del Centro, S.A. de C.V. y en virtud de ello, se le otorgó la posesión.

4. La adquisición referida se pactó a plazos y con el propósito de documentar la deuda, suscribió pagarés de acuerdo con lo dispuesto por la Ley General de Títulos y Operaciones de Crédito. Es pertinente destacar que, a partir de entonces, la señora Angélica Rivera Hurtado ha cubierto puntualmente su deuda a través de pagos verificados de su cuenta personal de cheques; el pago más reciente lo realizó el mes de octubre del presente ańo. Una vez que se cubra el monto total del adeudo, la parte vendedora otorgará la escritura pública a favor de la señora Angélica Rivera Hurtado, configurándose así la traslación de dominio a favor de ella.

5. Debe destacarse que la señora Angélica Rivera Hurtado en varias ocasiones ha hecho referencia en medios de comunicación a su casa y a la ampliación de la misma. Tal es el caso de la revista Hola, de fecha 1 de mayo de 2013.

El 18 de noviembre, el presidente Enrique Peña Nieto anunció que su esposa aclararía el tema de la adquisición de la propiedad en cuestión, por lo que esa noche en un video en YouTube la señora Angélica Rivera explicó que, si bien no tenía la obligación de rendir cuentas al no ser servidora pública, "asumía la explicación" [sic] como "un gesto de responsabilidad" (Guerrero, 2019). ${ }^{2}$ La señora Rivera concluye en el video que:

Ante todas las acusaciones que han puesto en duda mi honorabilidad, yo quiero dejar muy claro ante todos ustedes, los mexicanos, que yo no tengo nada que esconder, que yo he trabajado toda mi vida y que gracias a eso soy una mujer independiente, que he sido capaz de construir un patrimonio con honestidad y con todo mi trabajo. Siempre me he conducido con rectitud y por eso decidí explicarles todo lo relacionado con esta casa. Con la misma apertura con la que les he compartido los detalles de esta casa, quiero comunicarles que he tomado la decisión de vender los derechos derivados del contrato de compra venta porque yo no quiero que esto siga siendo un pretexto para ofender y difamar a mi familia.

${ }^{2}$ El video íntegro en: https://www.youtube.com/watch?v=Bh-h_WVuZac\&t=78s. 
Hoy estoy aquí para defender mi integridad, la de mis hijos y la de mi esposo. Junto a esta explicación que les he dado, en este momento, yo estoy haciendo pública documentación privada sin tener ninguna obligación porque, como lo dije antes, yo no soy servidora pública. Pero yo no puedo permitir que este tema ponga en duda mi honorabilidad y, sobre todo, que se pretenda dañar a mi familia. Buenas noches.

El 28 de noviembre de 2014, en el programa informativo radiofónico Atando Cabos, conducido por Denise Maerker, el periodista Daniel Moreno — director del portal informativo Animal Político - preguntó al Jefe de la Oficina de la Presidencia, Aurelio Nuño, si el tema de la Casa Blanca estaba cerrado y si ya se había aclarado lo que debía aclararse, a lo que este respondió que así era, que el tema estaba cerrado. Unos días más tarde, el 12 de diciembre, el Wall Street Journal publicó que el secretario de Hacienda, Luis Videgaray, había comprado una casa en Malinalco, Estado de México, a otra filial del Grupo Higa en octubre de 2012. Al mismo tiempo, apareció otra propiedad más del presidente Enrique Peña Nieto, una casa esta vez en Ixtapan de la Sal, que compró a otra filial del mismo grupo.

El 3 de febrero de 2015, el presidente Enrique Peña Nieto designó a Virgilio Andrade como titular de la Secretaría de la Función Pública y le ordenó investigar si en el tema del proceso de la adquisición de la Casa Blanca pudo haber habido conflicto de intereses o algún posible ilícito cometido, incluyendo la compra de la casa en Malinalco por parte del secretario de Hacienda y de la suya de Ixtapan de la Sal. Mientras tanto, el 15 de marzo la empresa Mvs dio por terminada su relación con la periodista Carmen Aristegui, luego de que esta última entrara en conflicto con la empresa por el previo despido de los periodistas que realizaron la investigación detrás del reportaje de la Casa Blanca.

El 21 de agosto de ese año, la SFP presentó las conclusiones de la investigación en las que manifiesta que, luego de tomar declaración a 111 funcionarios y revisar más de 33 contratos, quedaba claro que la adquisición de la Casa Blanca fue una operación entre particulares, con recursos legales de la señora Rivera, mientras que la compra de la casa de Ixtapan se realizó antes de que Enrique Peña Nieto llegara a la Presidencia, por lo que no había elementos para acreditar "el conflicto de interés". Con argumentos similares también exoneró al secretario de Hacienda. Un año después, el 18 de julio de 2016, en el marco de la promulgación del Sistema Nacional Anticorrupción, el presidente Enrique Peña Nieto ofreció una disculpa por las "interpretaciones que lastimaron e indignaron a los mexicanos [...] por lo que con toda humildad les pido perdón”. El cuadro 1 presenta los resultados de la cobertura de la Casa Blanca en los medios seleccio- 
CUADRO 1. La Casa Blanca, 9 de noviembre de 2014-21 de agosto de 2015

\begin{tabular}{|c|c|c|c|c|c|}
\hline Espacio informativo & $\begin{array}{l}\text { Núm. total } \\
\text { unidades }\end{array}$ & $\begin{array}{c}\text { Pro } \\
\text { gubernamentales }\end{array}$ & Criticas & $\begin{array}{c}\text { Fuentes } \\
\text { oficiales y pro } \\
\text { gubernamentales }\end{array}$ & $\begin{array}{l}\text { Fuentes } \\
\text { criticas }\end{array}$ \\
\hline $\begin{array}{l}\text { La Razón de México } \\
\text { (prensa) }\end{array}$ & $\begin{array}{c}4 \\
(100)\end{array}$ & $\begin{array}{c}4 \\
(100)\end{array}$ & $\begin{array}{c}0 \\
(0.0)\end{array}$ & $\begin{array}{c}3 \\
(100)\end{array}$ & $\begin{array}{c}0 \\
(0.0)\end{array}$ \\
\hline $\begin{array}{l}\text { Por la Mañana con Ciro } \\
\text { Gómez Leyva (radio) }\end{array}$ & $\begin{array}{c}6 \\
(100)\end{array}$ & $\begin{array}{c}5 \\
(83.0)\end{array}$ & $\begin{array}{c}1 \\
(17.0)\end{array}$ & $\begin{array}{c}4 \\
(80.0)\end{array}$ & $\begin{array}{c}1 \\
(20.0)\end{array}$ \\
\hline Milenio Diario (prensa) & $\begin{array}{c}5 \\
(100)\end{array}$ & $\begin{array}{c}4 \\
(80.0)\end{array}$ & $\begin{array}{c}1 \\
(20.0)\end{array}$ & $\begin{array}{c}3 \\
(75.0)\end{array}$ & $\begin{array}{c}1 \\
(25.0)\end{array}$ \\
\hline Hechos de la noche (TV) & $\begin{array}{c}3 \\
(100)\end{array}$ & $\begin{array}{c}3 \\
(100)\end{array}$ & $\begin{array}{c}0 \\
(0.0)\end{array}$ & $\begin{array}{c}2 \\
(100)\end{array}$ & $\begin{array}{c}0 \\
(0.0)\end{array}$ \\
\hline $\begin{array}{l}\text { Noticiero con Joaquín } \\
\text { López Dóriga (TV) }\end{array}$ & $\begin{array}{c}4 \\
(100)\end{array}$ & $\begin{array}{c}3 \\
(75.0)\end{array}$ & $\begin{array}{c}1 \\
(25.0)\end{array}$ & $\begin{array}{c}3 \\
(100)\end{array}$ & $\begin{array}{c}0 \\
(0.0)\end{array}$ \\
\hline Reforma (prensa) & $\begin{array}{c}18 \\
(100)\end{array}$ & $\begin{array}{c}7 \\
(39.0)\end{array}$ & $\begin{array}{c}11 \\
(61.0)\end{array}$ & $\begin{array}{c}3 \\
(37.5)\end{array}$ & $\begin{array}{c}5 \\
(62.5)\end{array}$ \\
\hline La Jornada (prensa) & $\begin{array}{c}20 \\
(100)\end{array}$ & $\begin{array}{c}5 \\
(25.0)\end{array}$ & $\begin{array}{c}15 \\
(75.0)\end{array}$ & $\begin{array}{c}2 \\
(18.1)\end{array}$ & $\begin{array}{c}9 \\
(81.8)\end{array}$ \\
\hline $\begin{array}{l}\text { MVs primera emisión con } \\
\text { Carmen Aristegui (radio)* }\end{array}$ & $\begin{array}{c}12 \\
(100)\end{array}$ & $\begin{array}{c}2 \\
(16.0)\end{array}$ & $\begin{array}{c}10 \\
(84.0)\end{array}$ & $\begin{array}{c}5 \\
(35.7)\end{array}$ & $\begin{array}{c}9 \\
(64.2)\end{array}$ \\
\hline Sin Embargo (Web) & $\begin{array}{c}10 \\
(100)\end{array}$ & $\begin{array}{c}3 \\
(30.0)\end{array}$ & $\begin{array}{c}7 \\
(70.0)\end{array}$ & $\begin{array}{c}5 \\
(41.6)\end{array}$ & $\begin{array}{c}7 \\
(58.3)\end{array}$ \\
\hline Animal Político (Web) & $\begin{array}{c}8 \\
(100)\end{array}$ & $\begin{array}{c}2 \\
(25.0)\end{array}$ & $\begin{array}{c}6 \\
(75.0)\end{array}$ & $\begin{array}{c}4 \\
(36.3)\end{array}$ & $\begin{array}{c}7 \\
(63.6)\end{array}$ \\
\hline
\end{tabular}

Fuente: Elaboración propia con base en datos de Efinfo (2016). *El 15 de marzo de 2015, la periodista Carmen Aristegui dejó de estar al frente del noticiero radiofónico Primera Emisión, al ser despedida junto con su equipo de colaboradores directos. En este caso, solo se toman en cuenta las unidades de análisis presentadas hasta esta fecha. Nota: porcentajes entre paréntesis.

nados desde el día en que aparece el reportaje y hasta el 21 de agosto de 2015, cuando se hacen públicas las conclusiones de la SFP.

En términos de unidades totales, los espacios que mayor número presentaron fueron La Jornada (20), Reforma (18) y MVS Primera Emisión (12), todos con mayor porcentaje de unidades con tendencias claramente críticas frente al encuadre oficial. Mientras que aquellos que tuvieron porcentajes más altos de tendencias favorables a la narrativa gubernamental fueron los espacios que reportaron menos unidades totales. Los espacios que presentan información con tendencia favorable al encuadre oficial son también los que menos unidades de análisis (notas, declaraciones, entrevistas) ofrecen sobre el tema en cuestión. 
GRÁFICA 1. Porcentaje de notas favorables y críticas a la narrativa oficial

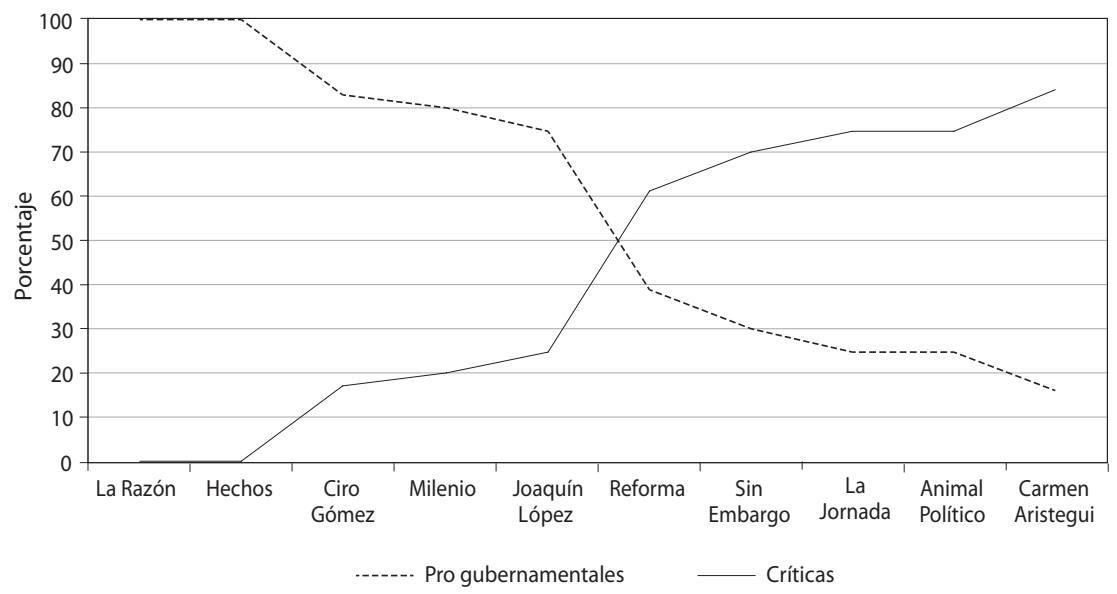

Fuente: Elaboración propia con base en datos de Efinfo (2016).

En términos porcentuales, hay aquí dos espacios informativos que presentaron 100 por ciento de unidades con tendencias favorables a esta narrativa: La Razón y Hechos de la Noche, mientras que Noticiero con Joaquín López Dóriga presentó 75 por ciento de unidades favorables. De lo anterior se desprende que si bien en términos totales en los once espacios, hay más unidades sobre el tema con tendencias críticas a la narrativa oficial, en términos porcentuales la forma de cobertura resulta bastante polarizada, tal como se aprecia en la gráfica 1.

En cuanto al uso de fuentes, el tema de la Casa Blanca muestra un empleo también muy polarizado de las mismas. Los cinco espacios informativos que recurren a un mayor porcentaje de fuentes oficiales y pro gubernamentales sobrepasan en todos los casos 75 por ciento, y en tres de ellos 100 por ciento de sus fuentes es de este tipo: La Razón, Hechos de la Noche y Noticiero. El caso de Ciro Gómez Leyva Por la Mañana registra un porcentaje muy alto de fuentes oficiales y pro gubernamentales $(80 \%)$.

Por su parte, los espacios informativos restantes emplean una proporción mayor de fuentes críticas, que oscila entre 58.3 por ciento en Sin Embargo y 81.8 por ciento en La Jornada. Queda claro que los espacios informativos que prefieren emplear más fuentes oficiales y pro gubernamentales lo hacen en porcentajes mucho más altos que aquellos que basaron sus unidades de análisis en fuentes críticas. Los espacios que ofrecen información con tendencia favorable son más 
intensos al apoyar su posición que los espacios que presentan información de tendencia más crítica. Asimismo, es importante señalar que, en todo caso, tanto las tendencias de la cobertura como el uso de las fuentes dejan ver una notable polarización informativa frente a la narrativa oficial en un tema que compromete la imagen del gobierno.

Una parte significativa de la información publicada en torno a la Casa Blanca se centró en intercambios verbales entre simpatizantes y críticos del gobierno, así como en los ataques entre los mismos. Estos factores dieron lugar a una cobertura más enfocada en el escándalo que en el análisis serio del caso y la investigación. Muchas de las notas reprodujeron declaraciones de personajes públicos sin vinculación realmente directa al tema. Tal es el caso de la publicada el 10 de marzo de 2015 en la portada de La Jornada, titulada "La vida de un zapatista vale más que la Casa Blanca”, en donde se reproducen las declaraciones del subcomandante Marcos quien afirmaba que "la vida de cualquier zapatista vale más que la Casa Blanca de (el presidente Enrique) Peńa Nieto y que todas las casas de los ricos del mundo juntas”. Por otra parte, están las notas referentes a las acusaciones entre las distintas bancadas parlamentarias, en donde no se da información más allá de la confrontación misma. En este rubro destacan piezas como la publicada por MVS Primera Emisión, con Carmen Aristegui, el 21 de noviembre de 2014, en donde se hace la crónica de cómo se "reventó" una sesión en la Cámara de Diputados, detallando que los diputados de izquierda demandaron la investigación del tema de La Casa Blanca; que la diputada del PRI, Angelina Carrillo, trató de defender a la señora Angélica Rivera, esposa del presidente, que los diputados del Partido de la Revolución Democrática (PRD) acusaron a los diputados del PRI de asesinos y que los diputados del PRI llamaban porros a los diputados del PRD. Están también las notas referentes a las reacciones en redes sociales con motivo de las explicaciones ofrecidas por Angélica Rivera. En este caso destacan notas como la publicada por Sin Embargo el 19 de noviembre de 2014, titulada "El affaire 'casa blanca' y el anuncio de Angélica Rivera se vuelven tema internacional” y en donde se detalla que el hashtag \#Angélica Rivera alcanzó el séptimo puesto mundial en la lista de Trending Topics de Twitter y encabezó el listado mexicano, seguido de otros temas relacionados con el escándalo de la Casa Blanca, como: \#YaMeCansé y otros hashtags. Finalmente, está el caso de las notas, como la publicada en la portada de La Jornada el 22 de agosto de 2015, que reprodujeron declaraciones del presidente Enrique Peña Nieto, una vez concluida la investigación de la SFP, en las que ofreció disculpas a quienes "pudieron haberse sentido ofendidos" por el caso y dijo estar "com- 
prometido para mostrar que las reformas en el país pueden cambiar la vida de las familias mexicanas en medio de la transparencia y combatiendo la corrupción".

\section{El caso de las Casas de Bartlett}

El 28 de agosto de 2019, el sitio web de noticias carlosloret.com publicó un reportaje especial realizado por la periodista Arelí Quintero titulado "Bartlett Bienes Raíces” (Quintero, 2019a). Paralelamente, el titular de dicho sitio web, el periodista Carlos Loret de Mola, dio difusión ese mismo día a dicho reportaje a través de su columna Historias de Reportero del diario El Universal y de su programa de radio, Asi las Cosas con Loret de W Radio. En el reportaje se señala que, de 2001 a la fecha, el titular actual de la Comisión Federal de Electricidad (CFE), Manuel Bartlett Díaz, adquirió 25 propiedades, con un valor aproximado de más de 800 millones de pesos. Estas propiedades ubicadas en zonas de lujo de la Ciudad de México, señala el reportaje, están registradas a nombre de la pareja sentimental de Bartlett, Julia Abdala, y de los hijos que ambos tienen de matrimonios anteriores. En su declaración patrimonial presentada en enero de 2019, Bartlett Díaz reportó tener una fortuna de 51 millones de pesos y ser dueño de dos edificios y tres terrenos. No obstante, como detalla Quintero, dicha fortuna sería, al menos, 16 veces mayor si se toman en cuenta las propiedades que el funcionario registró a nombre de su familia, las cuales no se mencionan en la declaración, y cuyas escrituras, de nuevo según el reportaje, reportan costos aparentemente subvaluados (Quintero, 2019b).

Unas horas después de que se publicó y se difundió el reportaje, Bartlett Díaz publicó un mensaje en su cuenta de Twitter argumentando que:

@CarlosLoret y su reportera @areliquinteroc han montado un sainete en radio con mentiras y afirmaciones que rechazo categóricamente. Periodismo venal. @El_Universal_Mx @WRADIOMexico (Bartlett, 2019).

Un día después, el 29 de agosto de 2019, Irma Eréndira Sandoval, secretaria de la Función Pública, dijo ante los medios de comunicación que Carlos Loret estaba "sacando fuera de contexto" [sic] información y añadió que "se tiene que revisar", ya que "son cuestiones que ocurrieron cuando no era funcionario público". Por su parte, el presidente de la república, Andrés Manuel López Obrador, declaró el 30 de agosto que:

Yo estoy seguro que el licenciado Bartlett va a informar. Son de estos reportajes que se hacen con propósito de afectar políticamente sin duda, pero todos tenemos la obligación de informar. Yo le tengo confianza al licenciado Bartlett (Cruz, 2019). 
El mandatario añadió que quienes realizaron el reportaje, son "los mismos que no quieren que se haga Santa Lucía ni que haya austeridad". Por otra parte, luego de haberse referido al caso en sus espacios informativos, los periodistas Leo Zuckerman y Pascal Beltrán del Río recibieron una carta por parte de la coordinación de comunicación corporativa de la CFE en la que el titular de dicha coordinación, Luis Bravo Navarro, increpó a los periodistas por conceder la razón al reportaje difundido por Loret. En el comunicado, cabe señalar, Bravo Navarro se refiere a Beltrán del Río como "sicario del periodismo" y de manera irónica a Zuckerman como "impoluto" (Etcétera, 2019).

Doce días después de que se publicara el reportaje, el 10 de septiembre, la Secretaría de la Función Pública lanzó un comunicado en el que se informó que, en atención a una denuncia anónima a través del Sistema Integral de Denuncias Ciudadanas (Sidec), se daba inicia a una investigación sobre la declaración patrimonial y de intereses de Manuel Bartlett, y señalaba que:

La apertura del expediente concuerda con la convicción de la secretaria Sandoval Ballesteros de - como ha sostenido previamente- no hacer un uso faccioso de la institución y que no se investiga por consigna, sino siempre en respeto a la legalidad (sFr, 2019a).

A la denuncia anónima que dio pie a la investigación, se sumaron otras denuncias, incluidas las realizadas por el Partido Acción Nacional (PAN) y el Partido de la Revolución Democrática por fraude y cohecho.

Más tarde, el 24 de septiembre de 2019, el periodista Carlos Loret publicó otro reportaje. En esta nueva investigación, realizada también por Arelí Quintero, se documenta la vinculación de Bartlett con doce empresas: dos en las que participa directamente, cinco de su pareja y cinco de su hijo, las cuales no aparecen en su declaración patrimonial. El reportaje señala el posible conflicto de interés que suponen, porque dos de esas empresas han sido contratistas del gobierno y al menos una lo sigue siendo, habiendo recibido un contrato de dos millones de pesos en el actual sexenio. Otra de esas empresas ofrece servicios relacionados con el sector energético (Quintero, 2019b).

De nueva cuenta, el presidente López Obrador (Martín, 2019) se refirió al caso como una campaña orquestada por los "conservadores" para manchar a su gobierno y volvió a manifestar su confianza en Bartlett que, por su cuenta, volvió a desestimar las acusaciones. Por su parte, Irma Eréndira Sandoval, en su comparecencia ante la Cámara de Diputados y ante los reclamos de los legisladores de oposición, quienes portaron máscaras de Manuel Bartlett, volvió a 
manifestar que la investigación se realizaría sin sesgos y con apego a la ley ( $\operatorname{Sin}$ Embargo, 2019b).

El 17 de octubre de 2019, el periodista Carlos Loret de Mola dio a conocer en sus espacios informativos que, de manera inusual, había recibido una notificación de la Secretaría de la Función Pública para colaborar en la investigación de presuntos casos de corrupción en Petróleos Mexicanos (Pemex) mediante la entrega del material documental con el que el periodista había realizado un reportaje llamado "Operación saqueo". En el oficio entregado al periodista la SFP:

[...] solicita su colaboración con esta autoridad investigadora, a fin de que dentro del término de 07 días hábiles, contando a partir del día siguiente a aquél en que surta efectos la notificación del presente oficio, tenga a bien remitir a esta autoridad administrativa copia certificada de toda la documentación con que cuente respecto de los hechos antes referidos, así como de los audios, videos y/o videograbaciones que tenga, en torno a la nota periodística relacionada con la empresa Black Cube y funcionarios y ex funcionarios de Petróleos Mexicanos (sFp, 2019a).

El periodista se negó a colaborar con la dependencia manifestando:

¿Será que la SFP escoge políticamente qué expedientes perseguir? ¿Será que un reportaje que denuncia corrupción en el sexenio pasado amerita una notificación inmediata a un periodista, pero no un reportaje que denuncia corrupción en el actual gobierno?” (Loret, 2019).

El 19 de diciembre de 2019, la secretaria de la Función Pública, Irma Eréndira Sandoval, ofreció una conferencia de prensa en la que dio a conocer que en la investigación realizada por la dependencia en torno a Manuel Bartlett no se encontraron indicios de enriquecimiento oculto u ocultamiento de conflicto de interés (El Financiero, 2019). Sandoval argumentó que:

De las constancias que integran la indagatoria, no se advierte que el servidor público haya tenido la obligación legal de manifestar esos inmuebles en sus declaraciones patrimoniales de 2018 y 2019 ya que con ninguno de sus propietarios mantiene una relación de matrimonio, concubinato o dependencia económica (sFP, 2019b).

Respecto al posible conflicto de intereses relacionado con las empresas en las que participa el funcionario, Sandoval dijo que Bartlett Díaz no tiene ninguna injerencia en la administración o control de las empresas por las que fue cuestionado en las denuncias presentadas, como tampoco ha intervenido en la aten- 
ción, tramitación o resolución de asuntos relacionados con las mismas (Animal Politico, 2019).

Ante la resolución, diversos miembros de la oposición, críticos y usuarios de redes sociales manifestaron molestia, comparando la investigación con la que realizara hace unos años la misma dependencia en el caso de la Casa Blanca de Enrique Peña Nieto. Por su parte, el presidente Andrés Manuel López Obrador expresó su conformidad con la investigación, haciendo hincapié en que las acusaciones fueron articuladas por sus detractores y retando a quienes le cuestionaron en su conferencia matutina del 20 de diciembre a demostrar la culpabilidad de Bartlett. “¿Cuáles son las transas?”, preguntó ese día el presidente (Aristegui Noticias, 2019a).

El cuadro 2 muestra el número y la orientación de las notas publicadas, así como de las fuentes, en doce medios nacionales, desde el día en que aparece

CUADRO 2. Las Casas de Bartlett, 28 de agosto de 2019-19 de diciembre de 2019

\begin{tabular}{|c|c|c|c|c|c|}
\hline Espacio informativo & $\begin{array}{l}\text { Núm. total } \\
\text { unidades }\end{array}$ & $\begin{array}{c}\text { Pro } \\
\text { gubernamentales }\end{array}$ & Criticas & $\begin{array}{c}\text { Fuentes } \\
\text { oficiales y pro } \\
\text { gubernamentales }\end{array}$ & $\begin{array}{l}\text { Fuentes } \\
\text { criticas }\end{array}$ \\
\hline La Jornada (prensa) & $\begin{array}{c}17 \\
(100)\end{array}$ & $\begin{array}{c}12 \\
(70.5)\end{array}$ & $\begin{array}{c}5 \\
(29.5)\end{array}$ & $\begin{array}{c}16 \\
(69.5)\end{array}$ & $\begin{array}{c}7 \\
(30.4)\end{array}$ \\
\hline La Razón (prensa) & $\begin{array}{c}9 \\
(100)\end{array}$ & $\begin{array}{c}5 \\
(55.5)\end{array}$ & $\begin{array}{c}4 \\
(44.5)\end{array}$ & $\begin{array}{c}5 \\
(31.2)\end{array}$ & $\begin{array}{c}11 \\
(68.7)\end{array}$ \\
\hline Reforma (prensa) & $\begin{array}{c}23 \\
(100)\end{array}$ & $\begin{array}{c}8 \\
(34.7)\end{array}$ & $\begin{array}{c}15 \\
(65.2)\end{array}$ & $\begin{array}{c}13 \\
(46.4)\end{array}$ & $\begin{array}{c}15 \\
(53.5)\end{array}$ \\
\hline Milenio Diario (prensa) & $\begin{array}{c}7 \\
(100)\end{array}$ & $\begin{array}{c}4 \\
(57.1)\end{array}$ & $\begin{array}{c}3 \\
(42.8)\end{array}$ & $\begin{array}{c}6 \\
(60.0)\end{array}$ & $\begin{array}{c}4 \\
(40.0)\end{array}$ \\
\hline Animal Político (Web) & $\begin{array}{c}5 \\
(100)\end{array}$ & $\begin{array}{c}4 \\
(80.0)\end{array}$ & $\begin{array}{c}1 \\
(20.0)\end{array}$ & $\begin{array}{c}7 \\
(77.7)\end{array}$ & $\begin{array}{c}2 \\
(22.2)\end{array}$ \\
\hline $\begin{array}{l}\text { En Punto Denise Maerker } \\
\text { (TV) }\end{array}$ & $\begin{array}{c}3 \\
(100)\end{array}$ & $\begin{array}{c}2 \\
(66.6)\end{array}$ & $\begin{array}{c}1 \\
(33.3)\end{array}$ & $\begin{array}{c}4 \\
(80.0)\end{array}$ & $\begin{array}{c}1 \\
(20.0)\end{array}$ \\
\hline Hechos de la Noche (TV) & $\begin{array}{c}5 \\
(100)\end{array}$ & $\begin{array}{c}5 \\
(100)\end{array}$ & $\begin{array}{c}0 \\
(0.0)\end{array}$ & $\begin{array}{c}5 \\
(100)\end{array}$ & $\begin{array}{c}0 \\
(0.0)\end{array}$ \\
\hline SinEmbargo (Web) & $\begin{array}{c}18 \\
(100)\end{array}$ & $\begin{array}{c}10 \\
(55.5)\end{array}$ & $\begin{array}{c}8 \\
(44.5)\end{array}$ & $\begin{array}{c}16 \\
(57.1)\end{array}$ & $\begin{array}{c}12 \\
(42.8)\end{array}$ \\
\hline $\begin{array}{l}\text { Por la Mañana con Ciro } \\
\text { Gómez Leyva (radio) }\end{array}$ & $\begin{array}{c}10 \\
(100)\end{array}$ & $\begin{array}{c}4 \\
(40.0)\end{array}$ & $\begin{array}{c}6 \\
(60.0)\end{array}$ & $\begin{array}{c}6 \\
(46.1)\end{array}$ & $\begin{array}{c}7 \\
(53.8)\end{array}$ \\
\hline $\begin{array}{l}\text { Aristeguien Vivo (radio/ } \\
\text { Web) }\end{array}$ & $\begin{array}{c}13 \\
(100)\end{array}$ & $\begin{array}{c}7 \\
(53.8)\end{array}$ & $\begin{array}{c}6 \\
(46.1)\end{array}$ & $\begin{array}{c}11 \\
(52.3)\end{array}$ & $\begin{array}{c}10 \\
(47.6)\end{array}$ \\
\hline
\end{tabular}

Fuente: Elaboración propia. Nota: porcentajes entre paréntesis. 
el reportaje en el sitio del periodista Carlos Loret, 28 de agosto de 2019, hasta el día en que la secretaria de la Función Pública declara cerrado el caso el 19 de diciembre del mismo año.

En términos de unidades totales, los espacios que mayor número presentaron fueron Reforma (23), Sin Embargo (18), La Jornada (17) y Aristegui en Vivo (13), y solo el primero con una tendencia crítica frente al encuadre oficial. A diferencia del caso de la Casa Blanca, aquí solo hay dos casos con una tendencia crítica frente a la narrativa gubernamental, Reforma (62.2\%) y Por la Mañana con Ciro Gómez Leyva (60\%), mientras que en el resto las tendencias favorables oscilan entre 53.8 por ciento (Aristegui en Vivo) y 100 por ciento (Hechos de la Noche). Esta vez no hay una relación entre aquellos medios favorables a la narrativa gubernamental y su bajo número de notas, como en el caso Casa Blanca. De este modo, hay una clara tendencia a presentar una cobertura favorable a la postura oficial en la mayoría de los espacios noticiosos, tal y como se ilustra en la gráfica 2 .

En cuanto al uso de fuentes, el caso las Casas de Bartlett, a diferencia del caso anterior, en donde los medios favorables sobrepasan 75 por ciento de fuentes favorables, solo tres medios lo hacen: Hechos de la Noche (100\%), En Punto (80\%) y Animal Político (77.7\%). Los más equilibrados en el uso de fuentes favorables y críticas son Aristegui en Vivo, Reforma, Sin Embargo y Ciro Gómez Leyva. Resul-

GRÁFICA 2. Porcentaje de notas favorables y críticas a la narrativa oficial

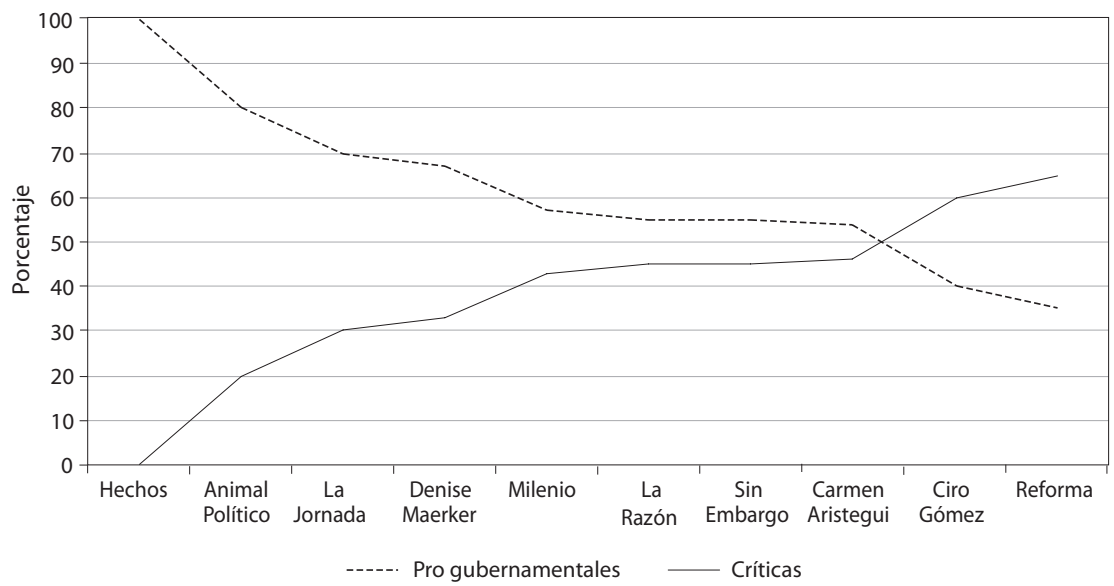

Fuente: Elaboración propia. 
ta curioso el caso de La Razón en donde se reportan muchas más fuentes críticas, a pesar de que, en cuanto a las piezas, en general terminan siendo más favorables, lo cual se explica por haber utilizado a varias fuentes críticas en pocas piezas informativas. Hay algunos espacios que resaltan por haber utilizado varias fuentes en sus notas: Aristegui Noticias, Sin Embargo, Por la Mañana y La Razón. Del mismo modo que en el caso Casa Blanca, los espacios televisivos son los que menos piezas informativas reportan, pero son los más intensos en su apoyo a la narrativa oficial, también con el menor número de fuentes utilizadas.

Cabe resaltar que, al igual que en el caso de la Casa Blanca, mucha información publicada se concentró en los intercambios verbales entre simpatizantes y críticos del gobierno, así como en los ataques que se generaban entre ellos, lo cual terminó por promover una cobertura más enfocada en el escándalo que en el análisis de lo sucedido. El portal informativo, Sin Embargo, por ejemplo, publicó una nota el 15 de septiembre de 2019 centrada en los tuits entre el ex presidente Felipe Calderón y Manuel Bartlett, titulada "Calderón a Bartlett: '¿En cuál de sus 47 casas se encuentra?' Bartlett responde: ‘'Deja de decir salud!” (Sin Embargo, 2019a). El 1 de octubre de ese año, Reforma publicaba otra nota con el título "¿Y sus bienes?... chu-chu-chu, se mofa", que enfatizaba tan solo la respuesta de Bartlett a los reporteros que preguntaban sobre los datos de sus propiedades (Morales, 2019). Otro ejemplo más es la nota del noticiero Hechos con Javier Alatorre acerca de la comparecencia de la secretaria de la Función Pública, Irma Eréndira Sandoval, ante diputados el 24 de octubre, la cual no se centra ni en las preguntas ni en las respuestas, sino en que los diputados del Partido Acción Nacional (PAN) portaban máscaras de la cara de Bartlett en la tribuna. Un número significativo de notas, como las publicadas después de la resolución de la SFP, se centraron en las declaraciones pronunciadas por el presidente López Obrador en sus conferencias matutinas en donde señalaba que el caso Bartlett era una campaña orquestada por la oposición y refrendó su apoyo a Manuel Bartlett. "A ver, ¿ahí cuáles son las transas?”, cuestionó el presidente López Obrador, luego de que la Secretaría de la Función Pública (SFP) informó que no encontró evidencias de conflicto de interés o corrupción contra Manuel Bartlett, director de la Comisión Federal de Electricidad (CFE).

\section{DISCUSIÓN}

Las teorías democráticas liberales suponen que los medios de comunicación son aliados indispensables para mantener una arena pública plural y abierta, en la que no sólo se garantice la libertad de expresión y de prensa, sino también el derecho 
de los ciudadanos a recibir información veraz, oportuna, de relevancia pública y en donde los medios puedan llevar a cabo un papel de vigilancia contra los abusos de poder y la corrupción. Esta última función es, sin duda, una pieza necesaria para pensar en una rendición de cuentas efectiva, en donde los servidores públicos expliquen y justifiquen sus actos y decisiones, así como también respondan administrativa y legalmente por sus faltas y omisiones. En México, a lo largo de su historia moderna, esta función de vigilancia, más que cualquier otra, se vio distorsionada por diferentes tipos de arreglos de intercambio clientelar entre los principales medios convencionales y el régimen político que imperó por más de setenta ańos.

Las diferentes alternancias en el gobierno federal que iniciaron en 2000 albergaron la esperanza no sólo de modificar las reglas para hacer más responsable el ejercicio del poder, sino también de generar las condiciones para un quehacer informativo más libre, plural y profesional. En el periodo, aunque se crearon importantes entramados legales e institucionales en el sentido de reforzar la responsabilidad pública de diferentes agencias y ámbitos de acción estatal, en gran medida se careció de la voluntad política real para permitir su funcionamiento efectivo. Por su parte, el panorama mediático, si bien se volvió más plural y libre, la mayoría de los medios convencionales buscaron acuerdos de intercambio de beneficios por apoyo político con los nuevos actores surgidos de la competencia electoral que en mucho reproducían los viejos arreglos con el régimen posrevolucionario. Como se ha mencionado, esto no significa que todos los medios y periodistas funcionaran de esta manera, pues en México siempre ha habido espacios críticos y profesionales y, gracias a la revolución digital, estos espacios cobraron mayor visibilidad. Sin embargo, sí se ha tratado de una tendencia predominante en el panorama mediático mexicano.

En este sentido, para la gran mayoría de los medios convencionales el costo fue el compromiso informativo, crítico y vigilante del periodismo que normalmente optaba por poner el ojo en temas que no supusieran una amenaza a la élite gobernante. El caso de la Casa Blanca muestra un sector duro de medios que apoyan la narrativa gubernamental y que difícilmente permiten en sus espacios la manifestación de voces críticas y alternativas. También es posible ver que hay otros medios - los digitales, entre ellos - que plantean una posición crítica. Sin embargo, en términos generales, no se comparte el tono ni el ángulo de la investigación original del equipo de mvs por parte de la mayor parte de los medios analizados, por lo que las denuncias de corrupción se mantienen en un sector tradicionalmente crítico del poder político, mientras que resulta claro que hay 
otros medios claramente alineados con la narrativa gubernamental, sobre todo los espacios informativos televisivos. Asimismo, conforme transcurre el tiempo, el foco informativo se va poniendo en el escándalo (por ejemplo, el "mensaje regañón" de la esposa del presidente Peña en YouTube) mucho más que en los detalles analíticos que lleven a comprender las dimensiones del caso (por ejemplo, lo que significa en términos de tráfico de influencias).

Para 2018, el hartazgo aparente de la población con los abusos de poder y corrupción favorecieron la llegada de un gobierno que prometía cambios importantes en el ejercicio de poder. Sin embargo, como se ha dicho, a dos años del inicio de este gobierno los resultados han estado muy lejos de lo prometido por razones atribuibles tanto a errores y omisiones propias del gobierno como a condiciones externas especialmente adversas durante 2020 a causa de la pandemia de covid-19, por lo que hasta ahora es difícil percibir una transformación hacia un ejercicio del poder más responsable. En lo que corresponde a la relación con los medios de comunicación, ha habido sin duda cambios importantes, positivos y negativos. Por un lado, el gobierno decidió terminar con el uso del gasto enorme en propaganda gubernamental que solía ser la principal base - que no la única- del intercambio clientelar para asegurar coberturas favorables o para que simplemente no se reportara sobre algunos de los asuntos menos convenientes para los gobiernos en turno. Estos recursos servían tanto para mantener a flote a medios sin públicos, como para incrementar las utilidades de los que sí contaban con ellos. En principio, esta situación supondría una extraordinaria ocasión para que los medios apostaran por acercarse a sus públicos, fortaleciendo su prestigio mediante un periodismo más profesional que les redituara en el mercado. La realidad, por desgracia, es que, en una parte importante de los medios convencionales, la limitación del gasto en publicidad oficial ha sido tomada más como una afrenta que como una oportunidad. Por el otro lado, el presidente López Obrador ha decidido no sólo centralizar todos los procesos de comunicación de su gobierno en sus conferencias diarias de cada mañana —lo cual genera enormes costos e ineficiencias en términos de comunicación-, sino que ha usado estos espacios para criticar a sus adversarios, entre los cuales ha señalado reiteradamente a medios y periodistas de forma poco responsable en un país en el que la violencia contra periodistas es de las más altas del mundo. Sin embargo, nuevamente la reacción de un número importante de medios informativos ha sido optar por una política editorial cuya lógica parece estar más orientada en exhibir al gobierno y sus varias fallas que en analizar la realidad e informar a la población. 
El caso de las Casas de Bartlett, si bien arroja una cobertura mucho menos dividida que la del caso Casa Blanca, sí muestra que los espacios informativos televisivos se alinean de forma más evidente que cualquier otro tipo de medio a las narrativas gubernamentales. Esto se ve en el número y tipo de notas: son los que menos cubren estos temas "incómodos", los que más favorables son en su cobertura y los que presentan los porcentajes más altos de fuentes oficiales. Esto no es casual visto que, a lo largo del tiempo, independientemente de los gobiernos en turno, Televisa y TV Azteca son los dos medios que mayores recursos reciben por publicidad oficial (Artículo 19, 2020c). También resalta, en términos generales, que los medios digitales son los que tienden al mayor equilibrio informativo. El caso de Reforma es interesante, pues en ambos temas se mantiene claramente crítico, aunque en el segundo las notas se centran más en el escándalo. También es notable el cambio en La Jornada, que en el caso Casa Blanca se muestra abiertamente crítico, pero en el caso de las Casas de Bartlett es claramente favorable al gobierno. ${ }^{3}$ En cuanto a la constante en los dos casos de enfatizar el escándalo una hipótesis - basada en el cambio de contexto derivado de las restricciones de la publicidad oficial y de la centralización informativa en la figura del actual presidente-, podría sugerir que, mientras en el caso de la Casa Blanca el énfasis en el escándalo podría orientarse a distraer del fondo sin sacrificar las ventas, en el de las Casas de Bartlett podría orientarse a exhibir para mantener las ventas. En cualquier caso, la cobertura muestra que los medios, salvo algunos espacios informativos concretos, todavía tienen una amplia oportunidad de fortalecer sus prácticas editoriales y su profesionalismo periodístico.

En suma, los vínculos más fuertes que se observan entre los dos estudios de caso aquí presentados y que refuerzan la idea de que los medios de comunicación en México no favorecen con su ejercicio del periodismo la rendición de cuentas desde el poder son: primero, ambas investigaciones surgieron desde medios (periodistas) con una evidente discrepancia con el gobierno en turno. Segundo, los reportajes originales encontraron cierto eco en otros medios, los cuales, sin embargo, no mostraron la disposición o la vocación por ampliar o enriquecer la información; en algunos casos, se limitaron simplemente a repetir la información original encuadrándola conforme a sus líneas editoriales ya determinadas a priori — críticas o favorables - por su relación particular con el poder. Tercero, además de la poca tendencia a enriquecer la información, se observa una clara propensión

\footnotetext{
${ }^{3}$ Es interesante notar que este periódico se ha convertido en el tercer mayor receptor de publicidad oficial en el gobierno del presidente López Obrador (Artículo 19, 2020c).
} 
a que estos temas públicos de relevancia deriven muy rápido en espectáculos mediáticos; si bien cada espectáculo a su manera y conforme al clima político y a las características y popularidad de los presidentes en turno. El caso de la Casa Blanca concluye como un espectáculo de linchamiento público, indignación y confrontación, combinado con las respuestas poco creíbles desde el poder. El caso de las Casas de Manuel Bartlett deriva en un espectáculo de increpación vitriólica entre el poder (el presidente mismo y el seńalado) y la prensa y sectores opositores. Y finalmente, lo más importante, en ambos casos la articulación entre el poder y el ejercicio periodístico, aunque tuvo un efecto (más notable en el primer caso) de dańo a la popularidad del gobierno, en ninguno de los dos la cobertura periodística impulsó un ejercicio auténtico de rendición de cuentas, a pesar de las múltiples respuestas que ofrecieron los actores involucrados y la Secretaría de la Función Pública. $\mathbf{G} \cong$

\section{REFERENCIAS}

Ades, A. y R. Di Tella (1999), "Rents, Competition, and Corruption", American Economic Review, 89(4), pp. 982-993.

Alatorre, J. (conductor) (2019), "Comparece secretaria de la Función Pública”, Hechos de la Noche, 24 de octubre, emisión de TV, Ciudad de México, TV Azteca.

Aristegui, C. (conductora) (2014), "Confrontación entre diputados de izquierda con diputados del PRI y del PVEM, por el caso Ayotzinapa y 'la Casa Blanca' revientan la sesión en San Lázaro", 21 de noviembre, MVS Primera Emisión, emisión de radio, Ciudad de México, Mvs 102.5.

Aristegui Noticias (2014), "Presidencia responde: La casa blanca es de Angélica Rivera”, 10 de noviembre, disponible en: https://article noticias.com/1011/mexico/presidencia-responde-la-casa-blanca-es-de-angelica-rivera-quien-es-economicamente-solvente/ [fecha de consulta: 20 de julio de 2020].

Aristegui Noticias (2019a), "AMLO reta a probar acusaciones contra Bartlett; 'no somos iguales', afirma”, 20 de diciembre, disponible en: https://aristeguinoticias.com/2012/ mexico/amlo-reta-a-probar-acusaciones-contra-bartlett-no-somos-iguales-afirma/ [fecha de consulta: 20 de julio de 2020].

Aristegui Noticias (2019b), "La casa blanca de Enrique Peña Nieto (investigación especial)", 9 de noviembre, disponible en: https://aristeguinoticias.com/0911/mexico/la-casablanca-de-enrique-pena-nieto/ [fecha de consulta: 20 de julio de 2020].

Animal Político (2019), "AMLO destaca prudencia de periodistas en conferencia; 'SI se pasan, ya saben'”, 15 de abril, disponible en: https://www.animalpolitico.com/2019/04/ amlo-periodistas-prudentes/ [fecha de consulta: 1 de agosto de 2020]. 
Arreola, F. (2015), "Ratings de radio", SDP Noticias, 22 de febrero, disponible en: https:// www.sdpnoticias.com/columnas/joaquin-ratings-radio-ciro-1.html [fecha de consulta: 25 de julio de 2020].

Artículo 19 (2020a), Disonancia: Voces en disputa, el informe anual 2019 de Article 19, 26 de mayo, disponible en: https://articulo19.org/disonancia/ [fecha de consulta: 1 de agosto de 2020].

Artículo 19 (2020b), Periodistas asesinados en México, en relación con su labor informativa, 15 de septiembre, disponible en: https://articulo19.org/periodistasasesinados/ [fecha de consulta: 1 de agosto de 2020].

Artículo 19 (2020c), Periodistas asesinados en México, en relación con su labor informativa, 15 de septiembre, disponible en: https://articulo19.org/periodistasasesinados/ [fecha de consulta: 12 de agosto de 2021].

Bartlett, M. [@ManuelBartlett] (2019), https://twitter.com/ManuelBartlett, Twitter, 28 de agosto, disponible en: https://twitter.com/ManuelBartlett/status/116691263 2084934656 [fecha de consulta: 2 de agosto de 2020].

Cruz, J.C. (2019), "Bartlett debe aclarar presunta riqueza, pero 'le tengo confianza': AMLO", Proceso, 30 de agosto, disponible en: https://www.proceso.com.mx/nacional/2019/8/30/ bartlett-debe-aclarar-presunta-riqueza-pero-le-tengo-confianza-amlo-230287.html [fecha de consulta: 2 de agosto de 2020].

Dahl, R.A. (1971), Polyarchy: Participation and Opposition, New Haven, Yale University Press.

Del Castillo Alemán, G. y G. Flores Ivich (2019), "La cobertura de la reforma educativa en México: Un asunto de medios y políticas”, Gestión y Política Pública, XXVIII(2), pp. 501-539.

Dunn, J. (1999), "Situating Democratic Political Accountability", en A. Przeworski, S.C. Stokes y B. Manin (eds.), Democracy, Accountability and Representation, Cambridge, Cambridge University Press.

DOF (Diario Oficial de la Federación) (2019a), Acuerdo por el que se establece la Política de Comunicación Social del Gobierno Federal, 17 de abril, disponible en: https://dof.gob. $\mathrm{mx} /$ nota_detalle.php?codigo $=5558048 \&$ fecha $=17 / 04 / 2019$ [fecha de consulta: 5 de agosto de 2020].

DOF (Diario Oficial de la Federación) (2019b), Acuerdo por el que se establecen los lineamientos generales para el registro y autorización de los programas de comunicación social y de promoción y publicidad de las dependencias y entidades de la Administración Pública Federal para el ejercicio fiscal 2019, 21 de septiembre, disponible en: https:// dof.gob.mx/nota_detalle.php?codigo=5556010\&fecha=29/01/2019 [fecha de consulta: 5 de agosto de 2020]. 
DOF (Diario Oficial de la Federación) (2020), Decreto por el que se autoriza a la Secretaría de Hacienda y Crédito Público a recibir de los concesionarios de estaciones de radio y televisión el pago del impuesto que se indica, 23 de abril, disponible en: https://dof.gob. $\mathrm{mx} /$ nota_detalle.php? codigo $=5592117 \&$ fecha $=23 / 04 / 2020$ [fecha de consulta: 5 de agosto de 2020].

Efinfo Sapi de c.v. (2016), Base de datos Eficiencia Informativa, Eficiencia Informativa, disponible en: https://www.efinf.com/web/ [fecha de consulta: septiembre de 2015 a abril de 2016].

Etcétera (2019), "En réplica a Excélsior, portavoz de la CFE insulta a Leo Zuckermann y Carlos Loret de Mola", 6 de septiembre, disponible en: https://www.etcetera.com.mx/ nacional/en-replica-excelsior-portavoz-de-la-cfe-insulta-leo-zuckermann-y-carlos-loretde-mola/ [fecha de consulta: 8 de agosto de 2020].

El Financiero (2019), "Función Pública exonera a Manuel Bartlett de conflicto de interés", 19 de diciembre, disponible en: https://www.elfinanciero.com.mx/nacional/no-seencontro-conflicto-de-interes-de-manuel-bartlett-en-investigaciones-funcion-publica [fecha de consulta: 2 de agosto de 2020].

Flores, L. (2020), "Banxico preve caída de hasta 8.8\% en economía mexicana por COVID-19”, El Universal, 27 de mayo, disponible en: https:/www.eluniversal.com.mx/ cartera/finanzas/banxico-preve-caida-de-hasta-88-en-economia-mexicana-por-covid-19 [fecha de consulta: 3 de agosto de 2020].

Flores, E. (2017), "Periodistas caídos en 64 años: El sexenio de Calderón es el más letal, le sigue el de EPN", Sin Embargo, 14 de diciembre, disponible en: https:/www.sinembargo.mx/20-12-2017/3360109 [[fecha de consulta: 12 de agosto de 2021].

Guerrero, M.A. (2019), ¿Cómo se informa hoy en México? Cinco tendencias noticiosas ante la narrativa oficial, Ciudad de México, Universidad Iberoamericana.

Guerrero, M.A. (2011), "Los medios de comunicación y el régimen político", en S. Loaeza, y J.F. Proud'homme (coords.), Procesos e instituciones públicas, Ciudad de México, El Colegio de México.

Henríquez, E. (2015), “EZLN: La vida de un zapatista vale más que la Casa Blanca”, La Jornada, 10 de marzo, pp. 1, 14.

Ipsos (2020), "Medición de la escucha/audiencia de radio", disponible en: https://www. ipsos.com/es-mx/medicion-de-la-escuchaaudiencia-de-radio [fecha de consulta: 3 de agosto de 2020].

Jiménez, N. y A. Urrutia (2020), "En México no hay un periodismo profesional: AMLO", La Jornada, 23 de abril, disponible en: https://www.jornada.com.mx/2020/04/23/ politica/010n2pol [fecha de consulta: 10 de agosto de 2020].

Kunicová, J. (2006), “Democratic Institutions and Corruption: Incentives and Constraints 
in Politics", en Susan Rose-Ackerman (ed.), International Handbook on the Economics of Corruption, Cheltenham, Edward Elgar Publishing, pp. 140-160, disponible en: https:/www.e-elgar.com/shop/usd/international-handbook-on-the-economics-ofcorruption-9781845422424.html [fecha de consulta: 1 de agosto de 2020].

La Silla Rota (2014), Casa blanca es de Rivera: Presidencia, 10 de noviembre, disponible en https://lasillarota.com/nacion/casa-blanca-es-de-rivera-presidencia/65679 [fecha de consulta: 12 de agosto de 2021].

Loaeza, S. (1989), “México 1968: Los orígenes de la transición”, Foro Internacional, 30(1), pp. 66-92.

Loret, C. (2019), "Revelamos escándalo... Y el gobierno nos emplaza”, El Universal, 17 de octubre, disponible en: https://www.eluniversal.com.mx/opinion/carlos-loret-de-mola/ revelamos-escandalo-y-el-gobierno-nos-emplaza [fecha de consulta: 10 de agosto de 2020].

Martín, N.S. (2019), "Bartlett enfrenta una campana de los conservadores: López Obrador", Proceso, 25 de septiembre, disponible en: https://www.proceso.com.mx/nacional/2019/9/25/ bartlett-enfrenta-una-campana-de-los-conservadores-lopez-obrador-231676.html [fecha de consulta: 2 de agosto de 2020].

Morales, A. (2019), “'Chuchuchú, chuchu' responde Bartlett a cuestionamientos sobre investigación de SFP”, El Universal, 30 de septiembre, disponible en: https://www.eluniversal.com.mx/nacion/chuchuchu-chuchu-responde-bartlett-cuestionamientos-sobreinvestigacion-de-sfp [fecha de consulta: 9 de agosto de 2020].

Myerson, R.B. (1993), "Effectiveness of Electoral Systems for Reducing Government Corruption: A Game-theoretic Analysis", Games and Economic Behavior, 5(1), pp. 118-132.

Ortega, E. (2020), "Fiscalía especial para periodistas, sin resolver 99.6\% de los casos", El Financiero, 3 de enero, disponible en: https://www.elfinanciero.com.mx/nacional/fiscalia-especial-para-periodistas-sin-resolver-99-6-de-los-casos [fecha de consulta: 1 de septiembre de 2020].

O'Donnell, G.A. (1998), "Horizontal Accountability in New Democracies, Journal of democracy, 9(3), pp. 112-126.

O’Donnell, G.A. y P.C. Schmitter (2013), Transitions from Authoritarian Rule: Tentative Conclusions about Uncertain Democracies, Baltimore, Johns Hopkins University Press. Proceso (2015), "Despide mvs a Carmen Aristegui”, 15 de marzo, disponible en: https:// www.proceso.com.mx/nacional/2015/3/15/despide-mvs-carmen-aristegui-144582.html [fecha de consulta: 25 de julio de 2020].

Quintero, A. (2019a), "Bartlett, bienes raíces", CarlosLoret.com, 28 de agosto, disponible en: https://www.carlosloret.com/2019/08/bartlett-bienes-raices/ [fecha de consulta: 10 de agosto de 2020]. 
Quintero, A. (2019b), "Bartlett, primero 23 casas, ahora 12 empresas", CarlosLoret.com, 24 de septiembre, disponible en: https://www.carlosloret.com/2019/09/bartlett-primero-23-casas-ahora-12-empresas/ [fecha de consulta: 9 de agosto de 2020].

SFP (Secretaría de la Función Pública) (2019a), "Función Pública abre investigación sobre declaración patrimonial del director general de la CFE (comunicado núm. 094)", disponible en: https://www.gob.mx/sfp/prensa/funcion-publica-abre-investigacionsobre-declaracion-patrimonial-del-director-general-de-la-cfe-216669 [fecha de consulta: 25 de julio de 2020].

SFP (Secretaría de la Función Pública) (2019b), "Palabras de la secretaria de la Función Pública, Irma Eréndira Sandoval Ballesteros, en la conferencia de prensa sobre Manuel Bartlett Diaz", disponible en: https://www.gob.mx/sfp/prensa/palabras-de-la-dra-irmaerendira-sandoval-ballesteros-secretaria-de-la-funcion-publica-durante-la-conferenciade-prensa-para-informar-sobre-la-investigacion-sobre-el-director-general-de-la-comision-federal-de-electricidad-ma?idiom $=e s$ [fecha de consulta: 25 de julio de 2020].

Sin Embargo (2014), "El affaire 'Casa blanca' y el anuncio de Angélica Rivera se vuelven tema internacional", 19 de noviembre, disponible en: https://www.sinembargo.mx/1911-2014/1171849 [fecha de consulta: 25 de julio de 2020].

Sin Embargo (2019a), "Calderón a Bartlett: ¿En cuál de sus 47 casas se encuentra? Le responde: 'Deja de decir salud'", 15 de septiembre, disponible en: https://www.sinembargo. $\mathrm{mx} / 15-09-2019 / 3645914$ [fecha de consulta: 15 de agosto de 2020].

Sin Embargo (2019b), "Manuel Bartlett dice que su declaración patrimonial está en regla; acusa campaña de desprestigio", 27 de septiembre, disponible en: https://www.sinembargo.mx/25-09-2019/3651691 [fecha de consulta:16 de agosto de 2020].

Vargas, R.E. (2015), "Peña se disculpa por agravios de la Casa Blanca", La Jornada, 22 de agosto, pp. 1, 3 .

Manuel Alejandro Guerrero es actualmente director del Departamento de Comunicación de la Universidad Iberoamericana en la Ciudad de México, miembro del Sistema Nacional de Investigadores, del Comité Ejecutivo de las Cátedras de la Organización de las Naciones Unidas para la Educación, la Ciencia y la Cultura (Unesco) en Comunicación, y coordinador académico del Servicio Profesional Electoral del Instituto Nacional Electoral (INE) de México. Es doctor en Ciencia Política por el Instituto Europeo Universitario de Florencia, Italia, y maestro en Estudios Latinoamericanos por la Universidad de Cambridge. Sus investigaciones se han enfocado en el papel de los medios de comunicación en las nuevas democracias, especialmente en la transparencia gubernamental y rendición de cuentas, y en los efectos de los medios de comunicación en las 
actitudes políticas. En estos temas tiene varios capítulos de libros, artículos y libros. Sus áreas de interés académico son: opinión pública, democracia, transparencia gubernamental, comportamiento del voto, rendición de cuentas.

Andrés Castillo es actualmente asistente de investigación en la Universidad Iberoamericana. Se desempeña también como consultor en comunicación política y monitoreo de medios de comunicación. 